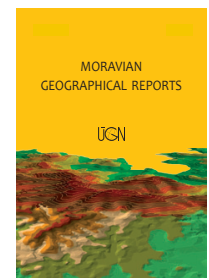

MORAVIAN GEOGRAPHICAL REPORTS

\title{
Urban agriculture and place-making: Narratives about place and space in Ghent, Brno and Bristol
}

\author{
Marlinde E. KOOPMANS ${ }^{\mathrm{a}, \mathrm{b}}$ *, Daniel KEECH ${ }^{\mathrm{c}}$, Lucie SOVOVÁ ${ }^{\mathrm{d}}$, Matt REED ${ }^{\mathrm{c}}$
}

\begin{abstract}
Despite rising enthusiasm for food growing among city dwellers, local authorities struggle to find space for urban agriculture (UA), both literally and figuratively. Consequently, UA often arises, sometimes temporarily, in marginal areas that are vulnerable to changes in planning designation. In the literature, spatial issues in relation to UA have either addressed structural questions of land use, governance and planning, or have highlighted social and personal benefits of UA. This paper aims to revisit and combine both streams of inquiry, viewing them as two co-constitutive forces that shape places through UA. The paper analyses three case studies in Brno, Ghent and Bristol, using a spatial lens that exposes important tensions as inherent characteristics of UA and conceptualises them as tensions within two space-narratives, namely abstract space and concrete place. It is suggested that UA, as a collective socio-cultural process, can transform functionally replicable spaces into unique places and thus contributes to place-making. This function should be recognised within urban planning circles, which should not only secure physical spaces to develop urban agriculture, but also create possibilities for local autonomous governance.
\end{abstract}

Keywords: Urban agriculture, space, place, place-making, urban planning, governance, Ghent (Belgium), Brno (Czech Republic), Bristol (England)

Article history: Received 24 January 2017; Accepted 8 June 2017; Published 30 September 2017

\section{Introduction}

Well within living memory, many Europeans could count professional farmers within their families. This number has decreased significantly over recent decades ${ }^{1}$. As a result, many European citizens are disconnected from agriculture and food production. Meanwhile, an increasing interest in reconnecting with farming and food cultures and practices has been observed among urban citizens (Scheromm, 2015).

In many cities, people start initiatives that relate to food production such as rooftop and community gardens, guerrilla gardening, as well as harvesting fruit trees in public parks and urban foraging walks. They get involved in urban agriculture (UA), which we understand as the growing, processing and distribution of food and other products through plant cultivation and animal husbandry in and around cities (Brown and Carter, 2003, p. 3).
The motivations for urban agriculture vary from the enjoyment of growing your own fresh and healthy vegetables, to the desire to be outdoors, as well as environmental concerns and a search for social interaction (McClintock et al., 2016; Scheromm, 2015). Apart from the individual motivations of citizens, urban agriculture is also promoted for its potential contribution to alleviate multiple urban problems, e.g. its contribution to socio-environmental justice, urban dwellers' health and nutrition, or the improvement of the urban environment (noise, dust and heat reduction, prevention of soil erosion, soil sealing, water management, providing refuges for natural organisms) (Lovell, 2010; van Veenhuizen, 2006). Many cities are initiating urban agriculture by developing local food strategies and supporting UA projects.

Simultaneously, city governments often struggle to find places for urban agriculture, both literally and figuratively.

\footnotetext{
${ }^{a}$ Department of Agricultural Economics, Ghent University, Ghent, Belgium

${ }^{\mathrm{b}}$ Social Sciences Unit, Flanders Research Institute of Agriculture, Fisheries and Food, Merelbeke, Belgium (*corresponding author, e-mail: Marlinde.Koopmans@Ilvo.vlaanderen.be)

${ }^{\mathrm{c}}$ Countryside and Community Research Institute, University of Gloucestershire, UK

${ }^{\mathrm{d}}$ Department of Environmental Studies, Faculty of Social Studies, Masaryk University in Brno, Czech Republic
}

\footnotetext{
${ }^{1}$ Between 2000 and 2010 the total number of farms in the EU-15 fell by just over one fifth (-22.8\%) (http://ec.europa.eu/eurostat/ statistics-explained/index.php/Agriculture_statistics_-_the_evolution_of_farm_holdings)
} 
The problems of 'acute land scarcity' (Zhu, 2012), 'high competition for land, soaring land prices' (de Zeeuw and Dubbeling, 2009) and 'access to urban land' (Rogge et al., 2016; Tornaghi, 2016; van Veenhuizen, 2006) are amongst the mostquoted challenges of urban and peri-urban agriculture. The pressure on urban land results not only from spatial but also economic limitations. Constrained city council budgets raise questions about the profitability of urban farms and gardens, and more implicitly, about the meaning and value of urban agriculture in cities (Cohen and Reynolds, 2014).

Consequently, we see that urban agriculture commonly emerges on land that is designated within official planning documents for land use other than food production: green spaces, brownfields and spaces in transition between zoning categories. Food production is often located "within the cracks of the system", in marginal urban spaces (Tornaghi, 2016, p. 2) with a temporary character. As a result, UA initiatives are vulnerable to changes in planning and other policies (Maloney, 2013; Spilkova and Vagner, 2016).

Spatial issues in urban agriculture have been approached from a broader perspective by geographers and spatial planners, addressing structural questions of land use, governance and planning (see Eizenberg, 2012; La Rosa et al., 2014; Maloney, 2013; Schmelzkopf, 2002; Smith et al., 2013; Spilkova and Vagner, 2016; Tornaghi, 2014). As early as 2002, Schmelzkopf examined a conflict over a community garden in New York. She argued that the conflict over the future of the allotment garden was symptomatic of broader power dynamics and the right to urban space (Lefebvre, 1991), a perspective that is common in this stream of research.

Another body of literature, closer to sociology and anthropology, approaches the spatial dimension of urban agriculture from the perspective of the value and cultural meaning of lived experience. Starting at the level of the individual, it explores how gardeners and other users build emotional connection to urban agriculture sites, and how people integrate these places into their everyday lives (Barthel et al., 2010; Bhatti and Church, 2001; Bhatti, 2006).

This paper aims to bring together those two streams of inquiry, viewing them as two co-constitutive forces that shape the places of urban agriculture. We use the spaceplace framework to investigate the replicability of urban agriculture and its functions. By analysing and comparing three cases through a spatial lens, we identify important tensions that are inherent to urban agriculture and discuss ways to make advances in how to overcome them. We do not suggest that these cases represent examples of struggles for urban land (see Blomley, 2008) or activist endeavours that confront the status quo. Instead, the analysis frames the cases as learning opportunities which offer new perspectives on urban land use and related governance mechanisms.

The article is structured as follows. The next section explores spatial perspectives with a focus on place, space and place-making. Section three describes the methodology and introduces the three cases that are analysed in this paper. In section four we discuss their role in the process of place-making and, finally, in section five, we finish with concluding remarks.

\section{Theoretical underpinnings of spatial perspectives}

Urban agriculture is a specific type of land use (Cohen and Reynolds, 2014). It is spatial because it reshapes a physical location and involves a "normative spatial vision" that contributes to the construction of ideas over use of space (Purcell, 2001, p. 182). In this paper, we conceptualise tensions of urban agriculture within a theoretical framework of space and place. The terms space and place have been used interchangeably and their ontological understandings have been subject to many discussions (Agnew, 2011).

Different meanings of space/place have been exercised since the time of the ancient Greeks, who held that: "Place ... is a part of the terrestrial surface that is not equivalent to any other, that cannot be exchanged with any other without everything changing. Instead with space [place as location] each part can be substituted for another without anything being altered, precisely when two things that have the same weight are moved from one side of a scale to another without compromising the balance." (Farinelli, 2003, p. 11 in Agnew, 2011).

Following this distinction, which is still present in contemporary theorisations of space, we use the term concrete place for the first meaning. Here, place is relational: "places give as well as acquire meaning in terms of what they offer morally and socially" (Agnew, 2011, p. 13). A place is socially constructed through the attribution of meanings by its users. This happens through symbols, images, ideas and feelings attached to a surrounding (Merrifield, 1993; Purcell, 2010). Place has an essential role in both personal and cultural identity (Relph, 1976, in Davenport and Anderson, 2005). The appreciation of place is therefore a more subjective one, and based on social relationships. It follows that a place is unique and almost irreplaceable, as the experience and relations it entails cannot easily be relocated.

In contrast, the second meaning, what we will call abstract space, is absolute, it is discursively constructed and conceived as a 'passive receptacle', as a thing 'in itself', a resource to be used and exchanged. According to Lefebvre (1991), this understanding of space is typical for urban planners, developers and architects. In this top-down perspective, space is valued by means of its functionality. Consequently, different areas are assigned for pre-defined functions such as transportation, building or public open space. This decision is, to a large extent, a pragmatic one, since spaces are understood as relatively replaceable or transferable, depending on the strategic opportunities they embody.

The conceptual framework of this paper is based on the idea that these two facets of place (i.e. on the one hand functional and inter-changeable, and on the other hand relational and unique) cannot be separated. The abstract space and the concrete space become intertwined. Places are continuously produced through the interaction and co-creation of different forces or space-narratives. Notwithstanding, these forces do not co-exist without tensions. As several authors from critical geography and political ecology perspectives point out (Barron, 2017; Eizenberg, 2012; McClintock, 2014), there is a hierarchy among the two narratives, with the more abstract space given primacy over the narrative of concrete place. The development of places is tied to administrative top-down planning mechanisms, and only in a secondary stage are spaces to become places, lived and experienced.

To overcome the primacy of the abstract space in shaping a place, the literature often refers to place-making processes (de Magalhăes and Madanipour, 2002) as active appropriation processes that open up the chance for a stronger identification with one's own living place (Franz 
et al., 2008). Fürst et al. (2004) explain 'place-making' as a "collective process of space arrangement with the aim to advance the usage and living quality of a space and to appropriate the space in a socio-emotional way" (in Franz et al., 2008, p. 323).

In this paper, we identify the spatial forces or narratives of the abstract space and the concrete place within three cases of urban agriculture, and we explore the tensions existing between them. We then show how urban agriculture contributes to urban place-making. That leads us to suggest that practices that support this process need to be effectively institutionalised in urban planning. Although the availability of physical space resulting from UA-friendly planning is an essential precondition, we claim that it is collective placemaking that truly gives spatial values to UA.

\section{Methodology}

\subsection{Introduction of the cases}

In this study, we compare three cases of urban agriculture in three medium-sized, post-industrial European cities: De Site in Ghent (Belgium), the Blue Finger in Bristol (England), and the Kraví hora allotments in Brno (Czech Republic). The three cities are, spatially and demographically, second-tier regional cities but with different municipal and historical contexts.

All three cases are examples of UA that involve locally produced and consumed vegetables. They reveal different combinations of environmental, social and economic functions, however, that result from urban agriculture practices (Koopmans et al., 2017). The main functions of De Site are social inclusion, citizen participation and the production of green space. Kraví hora has an important cultural function, it is a space for leisure and food selfprovisioning (Sovová, 2015). The Blue Finger is focused on food production but has also developed a significant political meaning. While we accept that UA has multiple functions in the three cases, by using a spatial lens we explore and compare one specific function they have in common: the function of place-making. Moreover, the cases represent different contexts in which urban agriculture is practised. Kraví hora in Brno is a traditional allotment garden. De Site in Ghent is a community space with both a community vegetable garden and allotments. The Blue Finger covers large tracts of periurban land, including some parcels that are cultivated by civil society groups for vegetable production. In this respect, the Blue Finger is distinctive because some of its land is functionally categorised as agricultural land already. Finally, different target groups are involved in the three case studies: from urban dwellers with high representations of elders and of young families in Brno, residents with a variety of difficult socio-economic circumstances in Ghent, to landowners and activists in Bristol.

All three cases have been the subjects of struggles for their future existence due to competing demands on urban land use. By analysing and comparing these cases from the spatial perspective, we discover similarities that allow for discussion and general remarks on the spatial context of urban agriculture. The case study areas are indicated in red on each map.

\subsubsection{De Site, Ghent, Belgium}

De Site is located in the Rabot neighbourhood in Ghent, a city of about 256,000 inhabitants. This densely populated neighbourhood has a relatively high percentage of Belgian residents with foreign roots and is one of Ghent's most deprived areas.

It was here in 2003 that the city development agency acquired an old industrial site of 7 hectares (ha) and demolished the buildings, leaving only the concrete floors of the former factories in place. The city council has plans to redevelop this area, mainly with housing. Only months after the demolition was finished, the area was unofficially claimed by local residents because they felt their area lacked public space. Later, a number of local civil society organisations and residents secured the council's approval and financial support to use 1 ha of the brownfield site as a temporary public space, which they called De Site ('the site'). The organisers presented their idea to the city council as an alternative strategy to engage people in the redevelopment process of the area.

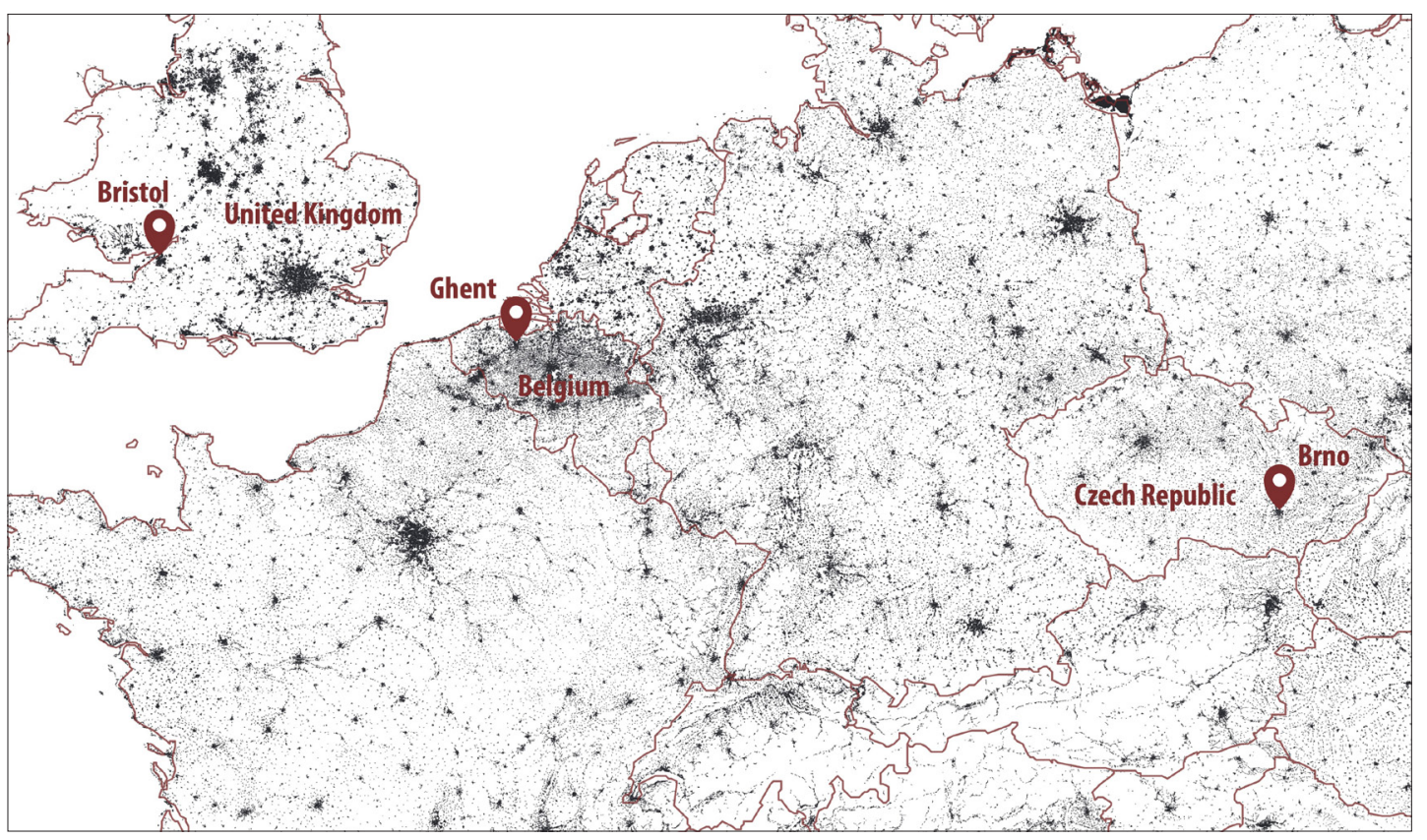

Fig. 1: Location of the three case studies in Europe (Build-up area in black)

Source: CORINE land cover, 2006 
De Site slowly developed as a multifunctional place with 160 allotment gardens, each $4 \mathrm{~m}^{2}$ in size. It also has an open-air cinema, a cycle track, a soccer field and a children's playground. A chicken coop with 30 laying hens and a field of 0.3 ha were added. In the field a variety of vegetables are produced, sold and processed in a local shop and restaurant, both offering products at lower prices to people with a low income. Eventually, a 10-year lease for De Site was secured in 2016.

\subsubsection{Kraví hora, Brno, Czech Republic}

Kraví hora (literally 'Cow hill') is a hill in the centre of Brno, the second largest city in the Czech Republic with about 380,000 inhabitants. Three allotments are located on the hill, covering a total of 14 ha of land divided into 575 individual plots of 200-250 $\mathrm{m}^{2}$. The first allotment at Kraví hora was established in 1934 and the remaining two shortly after World War II. The land is owned by the city council and rented to three branches of the Czech Gardeners' Association, the main body administering allotment gardens at the national level. These organisations then sublet individual plots to gardeners and are responsible for collecting fees, organising the maintenance of common areas and managing the allotments as a whole.

In terms of land use categories, the current master plan for Brno classifies the entire hill as public greenery with recreational functions. This classification does not fully capture the diversity of (actual) land uses that are present on the hill which, in addition to the allotments, include a public park, an outdoor sports centre, a swimming pool, an astronomical observatory and several buildings used by different owners. "Recreation" is a broad term - and different opinions of what urban recreational greenery should offer, in

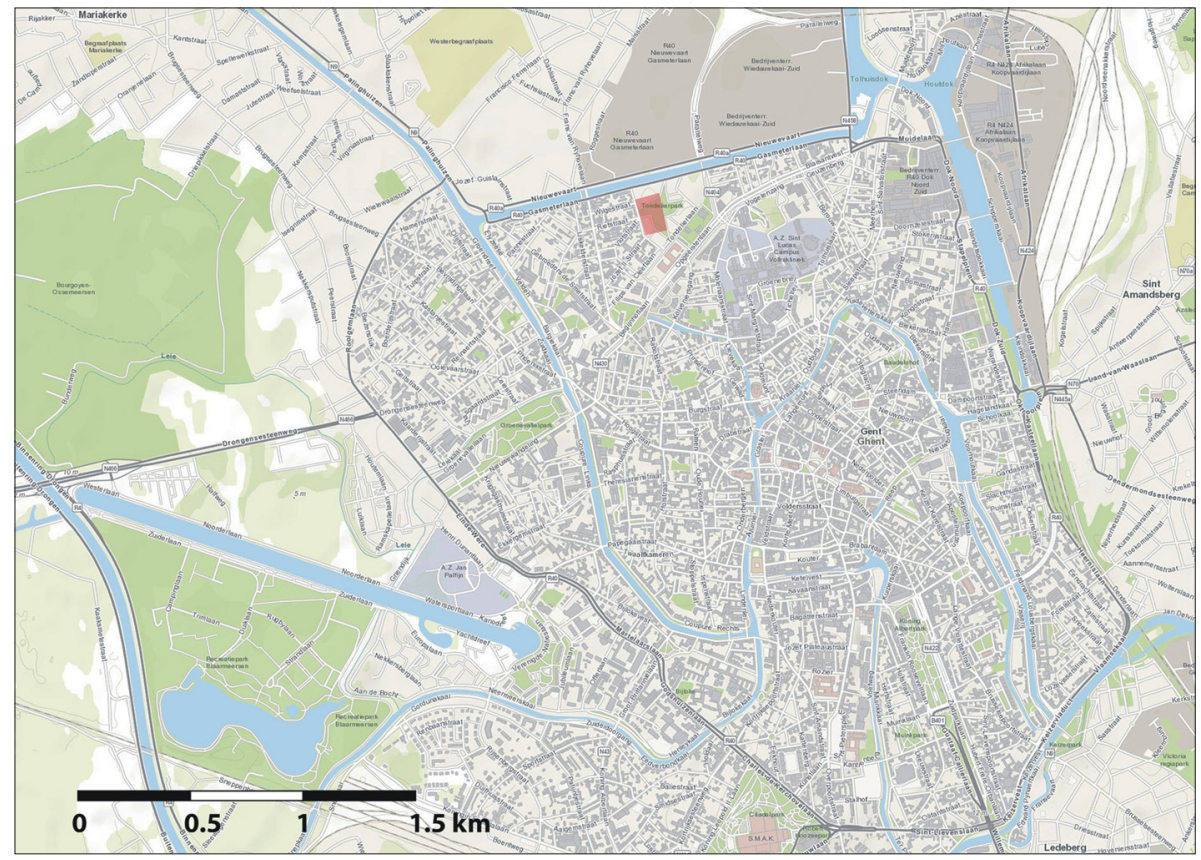

Fig. 2: Location of De Site in Ghent. Source: Esri.ArcGIS, 2017

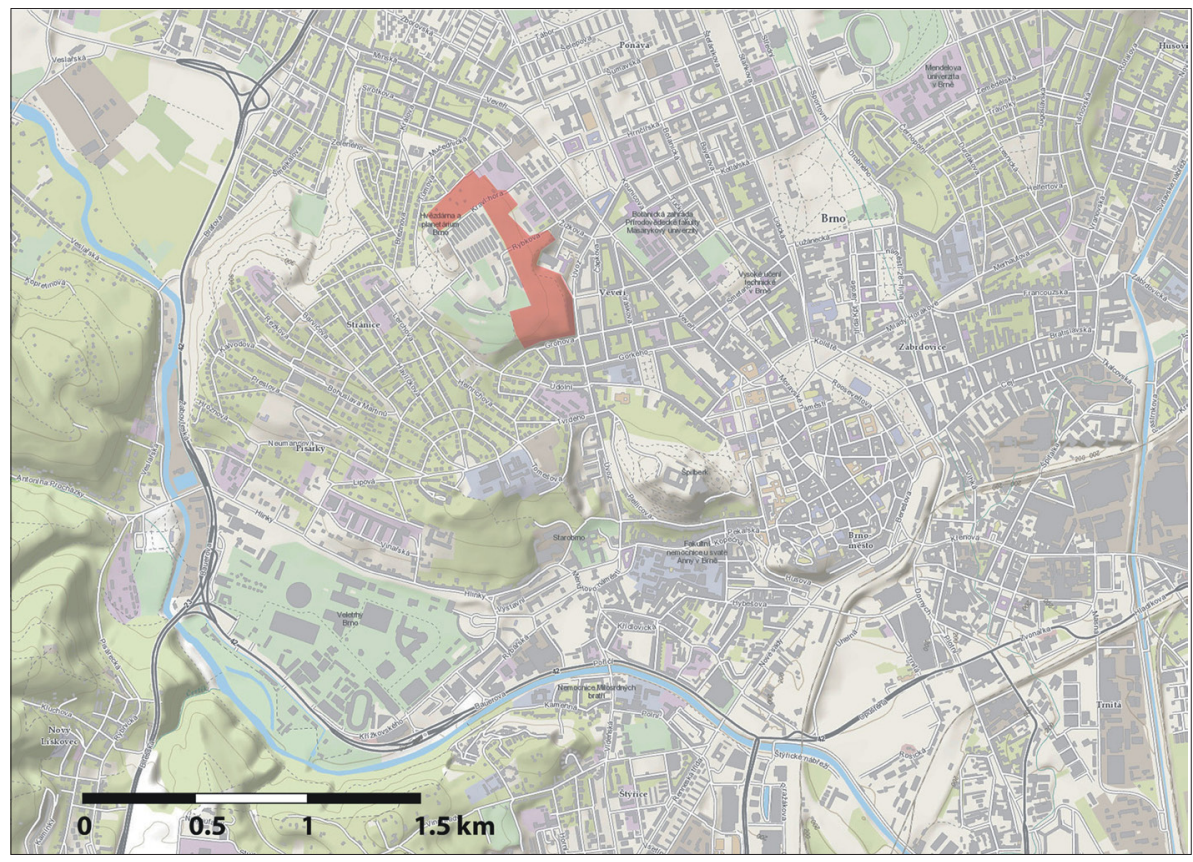

Fig. 3: Location of Kraví hora in Brno. Source: Esri.ArcGIS, 2017 


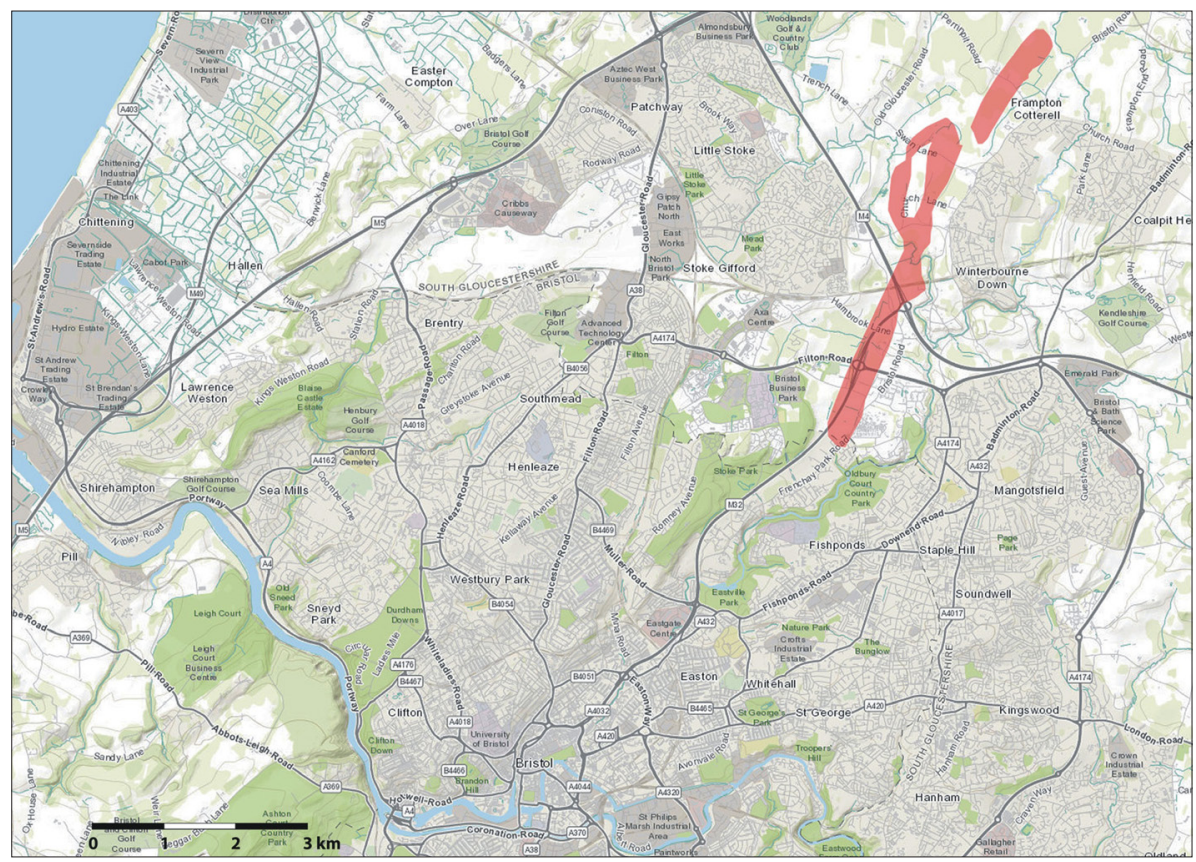

Fig. 4: Location of the Blue Finger in Bristol. Source: Esri.ArcGIS, 2017 (Note: scale differs from Figures 2 and 3)

which way and for whom, have been the centre of disputes over Kraví hora as well as other Czech allotments (see, for example, Pauknerova and Gibas, 2011).

\subsubsection{The Blue Finger, Bristol, England, UK}

The Blue Finger differs from the preceding case studies, which are discreet and delineated areas of their respective inner cities used for vegetable cultivation. The Blue Finger is, firstly, a concept: the name given to a strip of agricultural land covering 400 hectares on the edge of Bristol, a city with a population of 449,000 in south-west England. The Blue Finger stretches from the edge of Bristol's city centre, crosses the municipal boundary into the suburbs and into the rural countryside of the neighbouring local authority area of South Gloucestershire.

In addition to its finger-like outline - the Blue Finger is not more than $500 \mathrm{~m}$ wide but almost $20 \mathrm{~km}$ long - its name is linked to the blue shading that distinguishes the highest quality of agricultural land ('Grade 1: Best and Most Versatile') on soil classification maps in the UK. Land around Bristol, in common with much of the region and adjacent areas of Wales, is predominantly of lower agricultural grades, thus making the Blue Finger unique.

Secondly, the Blue Finger is an aspiration articulated by a local network, The Blue Finger Alliance (BFA), founded in 2012, which has campaigned for the protection of the agricultural function of the land as a contribution to the city's transition towards environmental sustainability, and to promote opportunities for agricultural jobs. To date some BFA activities have included compiling a register of the many landowners of the Blue Finger, encouraging Bristol City and South Gloucestershire councils to work together to support BFA objectives, and to develop public events and awareness-raising activities, including walks. BFA has also championed the Bristol 'Declaration of Soils', a manifesto seeking to prioritise the protection of soils as part of a systematic shift towards sustainable living.

The land has a diffuse, mainly private ownership but includes some parcels owned by the city council. These include extensive glasshouses, formerly used to cultivate flowers and shrubs for municipal planting. In what seems a fitting acknowledgement of this horticultural heritage, the council offered temporary leases to the community group 'Feed Bristol'. The southern tip of the Blue Finger includes the Stapleton (municipal) Allotments.

\subsection{Data collection and research process}

The research was based on case studies using exploratory, qualitative methodologies (Creswell, 2014; Yin, 2003). Data for Ghent and Bristol were collected within the framework of the European Commission Seventh Framework research project SUPURBfood (agreement 312126). This involved a minimum of 15 semi-structured interviews with key stakeholders in each city, including civil society activists, UA coordinators and municipal officials. They were asked about the origins and activities of UA and the challenges and opportunities facing these activities, in their respective cities. Additionally, secondary details about the UA initiatives were collected from websites, news reports and observations gleaned from events.

In the case of Brno, data were collected separately as part of the postgraduate thesis of one of the authors. Semistructured interviews were conducted with allotment association representatives and individual gardeners. Three interviews with allotment representatives covered details about the area, the number and demographic characteristics of the users, prevalent ways of using the gardens, ownership, and organisational structure. Thirteen interviews with allotment users inquired into their motivations and their relationship to the garden and the allotment community (see Sovová, 2015). Data collection also included non-participant observation (Gray, 2004).

For this paper, these two data sets were integrated and analysed independently from their original purposes. Rather, the data were analysed in relation to the spatial perspective of this paper, focusing on aspects of place, space and placemaking. The observations and interpretations are therefore exploratory. This ex-post, abductive inference has been used in order to highlight the inherent tensions involved 
in UA. The merit of this method lies in its ability to bring together case studies which have not been considered in the constellation set out here. Such an open-ended data analysis helps avoid what Gibson-Graham (2014, p. 148) term "strong theories" - that is, powerful discourses that seem to organise events into understandable patterns but that may in fact result in reinforcing inaccurate presumptions. The analysis is strengthened by the fact that it is grounded in the comparison of three different cases and builds on existing scholarship on urban agriculture.

\section{Results: How urban agriculture shapes urban places}

In this section we elaborate on the situation of the three initiatives in relation to space and place, integrating our data analysis with current debates on urban agriculture.

First, the cases are introduced in the light of a narrative of abstract space, describing its situation in the current planning. Second, narratives about concrete place are explored. Based on this, the role of urban agriculture in the process of place-making is explored. Finally, we articulate lessons on governance that can be useful to overcome the tensions between the two space-narratives and to support the place-making function of urban agriculture.

\subsection{Urban agriculture in the planning system - narratives of abstract space}

The position of all three initiatives within their cities' spatial plans is precarious. At Kraví hora, the replacement of the allotments with a public park or sport facilities has been discussed continously for the last decade, despite the long tradition of the allotments. This situation is perceived as a threat, since the rent contracts with the municipality are always temporary (typically valid for one year). The main argument has been that since the allotments are located on public (municipal) land, they should also be accessible to the public, contrary to the current situation where the allotments are fenced and open for members only. The fencing of these relatively large areas also hinders the permeability of the surroundings for pedestrians. A proposed solution to this was the creation of public paths through the allotments; however, for the gardeners this would have a significant impact on their experience of the place (see below).

The case of Ghent reveals unexpected flexibility in the interpretation of rigid planning regulations, which specify fixed functional land use categories. The land at De Site was functionally re-categorised from an industrial to a housing function. While the land remained undeveloped, however, local residents started to use it for vegetable cultivation. Normally, temporary activities that fall outside the official functional land use categories are not permitted, and not even considered unless representations come directly from the land owners (in this case the council itself). The local social benefits of the gardening activity, however, were used as the justification to negotiate temporary, official occupation and use. This highlights the ephemeral nature of De Site in its current location.

In Bristol, local controversy has been caused by proposals for a new public transport network, which affect both Feed Bristol and the Stapleton Allotments. In 2015, Bristol was awarded the accolade of European Green Capital (EGC), secured in significant part by the city's proposals for sustainable transport.
In Bristol and Ghent, both councils made efforts to identify spaces to replace those being earmarked for development. In Bristol, however, the proposed replacement sites did not respond to the objectives of protecting Grade 1 soil quality in the Blue Finger. In Ghent the city council, which recognises the contribution that De Site makes to its social cohesion policies. It remains to be seen however, whether the promised replacement of one piece of land by another, elsewhere although in the same neighbourhood, will offer similar place-making opportunities as revealed by De Site.

The preceding section has described how all 3 cases reveal uncertainty, because UA was either an unintended consequence or a contested interpretation of sub-optimal spatial planning approaches. This has resulted in tensions which seem to be iconic and inherent to UA, so often located on 'transitional' or marginal spaces (Tornaghi, 2014). As illustrated in Bristol and Brno, urban food production spaces are forced to compete with 'recreational green space', or are regarded as resources available for certain strategic visions, rather than enjoying their own strategic categorisation in city plans (Tornaghi, 2016). As detailed in the next section, an abstract approach fails to accommodate the specifics of concrete places, which are captured by another set of narratives developed by users.

\subsection{Narratives of concrete place}

The parallel space narratives in all three cases revolve around the active engagement of people, which results in intimate connections and the transformation of purely functional space into meaningful place. In this section, we first discuss the observed appreciation of and identification with place on an individual level, and then continue to examine the broader cultural context of these relationships. Finally, the presented UA initiatives are shaped and experienced through collective management. This links to conclusions on place-making and its governance, which are discussed in the final section.

\subsubsection{Personal identification}

A place is shaped through the meanings that people imbue it with, and which are informed by and acquired through what a place offers (Agnew, 2011). Ideas and feelings attached to a place are expressions of this. They illustrate how people identify themselves in relation to the place. The three cases explored here reveal the reciprocal process of personal and place identification in differing ways. First, in Brno, the narratives indicate how Kraví hora both shapes and is an expression of peoples' personal identity. In many ways, gardeners from Kraví hora experience their plots as a part of home, a phenomenon described previously by Bhatti and Church (2001). Despite being rented, it is not unusual that plots are passed through family generations and their users feel very rooted there:

"We've had this garden since I was ten years old. When we first came here, there was just bare earth and a toolbox. Everything that's here, all the trees were planted by my parents or me. My dad built the shed. It is all their work and I am taking over now."

The garden is perceived as a place of intimacy and safety. The individual plots within the allotment are separated only by paths or low hedges and their size means that gardeners have no choice but to share their privacy with their neighbours. Most of the respondents find this close cohabitation unproblematic. Common interest, familiarity and regular contact between neighbouring gardeners 
reinforces collective identity. Contrarily, the prospect of the allotments being publicly accessible is perceived as an intrusion that disturbs the appreciated home-like intimacy:

"I couldn't even wear my swimsuit if people were walking around."

"'They want to come to the allotments for a walk...? Well how about I go eat my lunch in their office or their living room?', another gardener reacted."

Allotment members often mention the ability to engage in gardening and spend time in a pleasant, green environment, but it is the sense of "being at home" which distinguishes the allotment from other places where these activities might be performed.

Similarly, De Site is valued for stimulating a 'feeling of belonging and meaningfulness'. A member of the coordinating civil organisation said:

"All 70 gardeners strongly identify themselves as [a] 'gardener of De Site'. In addition, 250 volunteers also feel part of De Site. Together, we feel responsible for maintaining the area."

Among them are the homeless and other sans-papiers residents - a group of people that are left out of the economy that get involved in productive, meaningful activity by producing food at De Site. Volunteers get 'paid' with a local currency, called 'Torreke', for the work they do in growing food. Torreke can be spent in the local social restaurant and in a local grocery shop. In this way marginalised residents have their place in the neighbourhood, both literally and figuratively:

"The place creates pride among the users. People say:

'This is my place, either to play football, to produce food or just to meet other people'."

In other words, at De Site this feeling of belonging to a shared place helps in reconnecting people of different ages and socio-economic backgrounds and cultures. Also in Bristol, diverse groups of users came together at specific locations through a shared interest in food growing. The wider identity which has developed around the Blue Finger, however, is political. The BFA promotes an ethical and political proposition which connects the Blue Finger's intrinsic soil fertility, its position on the fringe of the city and its historical productivity, with a narrative that suggests that food production capacity is an attribute of Bristol, and a prerequisite for all sustainable cities. In its campaign, BFA highlighted that the land's importance to wildlife and its high soil fertility gives local people the opportunity to grow food in this 'very special area'. By taking to the branches, they refused to allow tree felling to start on 'our land'2.

To summarise, the cases illustrate how people give specific meanings to places based on their expectations and needs, and at the same time, they recreate their own personal identities through interactions with the place. This process is self-perpetuating to some extent: the appreciation of the place determines how people engage with it, and vice versa. Since all of our cases involve groups of users, there is also a factor of shared collective identity, discussed further below. The concrete place narrative also has implications for the replicability of the place and its functions, because these are not only based on physical characteristics but also have a strong social dimension. These dimensions cause tensions because the values that shape place identities are often sub-ordinated in favour of land use functions in abstract-space debates.

\subsubsection{Cultural meaning/identity}

The cases contain narratives that illustrate the construction of cultural identity. Tornaghi (2016) has suggested that food provisioning (including growing, preparing, sharing or preserving food) can facilitate both personal experiences, as well as the creation of culturally embedded practices. Food growing in cities thus represents lived manifestations of culture and continuing (if often interrupted) traditions of food production. Case study narratives affirm this and try to justify the presence of food growing in cities, specifically by building on traditions and re-enacting cultures. For example, in Bristol, there is an explicit link to historical market gardening. For several years, an energetic and consultative process of developing a sustainable food strategy for the city has been in progress (Carey, 2013). This has included the establishment of a Food Policy Council and support for a range of local food initiatives in connection with EGC. The city's health service commissioned a study of the potential to localise food provisioning, which included the re-evaluation of the city's wholesale market and an estimation of the quantity of food that could be produced within the city, for example in urban parks (Carey, 2011).

In the Czech Republic, food growing is considered as part of national identity, together with many different ways of preserving foods and all kinds of do-it-yourself house and garden improvements (Duffková, 2002, de Hoop and Jehlička, 2017). The Kraví hora allotments are but one manifestation of this culture, including their particular aesthetic appearance. For the older generation, knowing how to grow and prepare food is part of common sense, and the garden is sometimes linked to the memories of growing up in the countryside. Home-grown food is generally perceived as healthier, tastier and generally 'proper'. Given the current level of urbanisation, however, urban gardens may represent one of the few practical chances for younger generations to learn about food production.

In Ghent, people from different backgrounds share their knowledge and culture about food production. For some this means recreating rural cultures in an urban context:

"De Site started based on the needs that existed within the neighbourhood. The needs are very much correlated to the cultural values the people have. The majority of the gardeners have a Turkish background and used to live in an agricultural area where they already produced food themselves. They literally said: "We would like to grow vegetables here'."

While food culture is part of urban lifestyle (exemplified by Bristol's annual Food Connections festival), cities tend to dedicate greater attention to strategic arrangements for post-production stages of the food chain, including retail (street markets, shops and restaurants), processing (abattoirs and food factories linked to distribution arteries), and to designs for domestic food spaces (see Parham, 2015 for a comprehensive summary). In contrast, food production has been largely fixed into rural settings. It is generally accepted that agricultural landscapes are cultural, coproduced by people and nature: "land as culture" (Clifford

\footnotetext{
${ }^{2}$ See https://www.theguardian.com/uk-news/2015/feb/02/bristol-bus-protesters-trees-european-green-capital-2015 (Last accessed November 30, 2016).
} 
and King, 2006, ix). Part of the acceptability of the concept of cultural landscape in the rural arena relates to a degree of continuity in landscape management, which results in, for example, patchworks of fields and their boundaries, functional and vernacular architecture and particular habitats. But cities, while no less co-produced than the countryside, are highly dynamic and land use continuity is harder to imagine. This can hinder the possibilities for food production and the associated cultural expressions.

\subsubsection{The collective dimension of place}

The lack of land use continuity in cities has an impact on the creation of places. As urbanisation and migration grow, many people experience what can be described as uprootedness or placelessness (Friedmann, 2010), and therefore the development of valued places within cities has become all the more precious (Perdikogianni, 2007). According to Proshansky et al. (1983), attachment to a place reflects "a sense of belonging and purpose which give meaning to his or her life" (in Davenport and Anderson, 2005, p. 90). At the same time, growing urbanisation and multiple demands for urban land create pressure for efficient spatial planning, sometimes with the result that little space is 'left to people'. The three cases illustrate how people have been able to identify with a place through a process of active but also collective appropriation. They do not just consume a place, as may be the case in recreational spaces such as parks, but actively shape and maintain it.

The collective dimension in this process of appropriation and identification is important in this regard. Collective management takes on different forms in the three cases. In all of them, however, the communities are defined - not only by shared space but also by shared responsibilities and interests, which in turn give grounds to a collective identity and shared relation to the place.

For example, in Brno, although people feel personal attachment to their individual plots, these are understood as part of a bigger whole, the functioning of which depends on participatory organisation and community cohesion. This collective dimension is an intrinsic characteristic of the allotment, for better or worse: in some cases, internal conflicts arise, while elsewhere gardeners list the friendship with their neighbours as a highly-appreciated feature of the allotment. Either way, it differentiates the allotment from both entirely public (i.e. open for everybody) and entirely private places.

This leads to our hypothesis that, through a culturally embedded activity such as food production, spaces can become meaningful collective places. It is acknowledged that although they are not open to everyone, such places are meaningful to particular groups. The places and the communities, that is, the spatial and the social, are mutually dependent: the meaning of place is strengthened when produced collectively, a process which simultaneously bolsters the community (Barron, 2017; Eizenberg, 2012). We observe this through the names given to places/communities, as they attempt to present themselves as collectives linked to locations. In the three cases, this is confirmed by organisational structures that represent collective identities and needs in negotiations with the authorities.

In the literature this process where social values of place become part of the design has been referred to as placemaking. In other words, despite their marginal position in spatial planning, the cases illustrate a place-making function within their cities. This carries implications for the governance of UA.

\subsection{Challenges for governance to support place-making}

As demonstrated in the previous section, the three cases illustrate how UA can play a role in shaping and expressing people's personal and cultural identity. In Brno and Ghent, users address intrinsic values of trust, safety and being part of a spatially defined community. The Bristol case carries moral and political significance for local activists who share the vision of the value of soil as a part of urban food security and sustainable development. The assertions of each group in the case studies express values that are more relational than functional, and as such constitute narratives of concrete place. In the light of this, the struggle for land experienced in each case is not necessarily one between citizens and the authorities, but between a set of interacting and sometimes conflicting space-narratives.

The tensions present in UA illustrate that traditional planning and public consultation methods struggle to secure meaningful public participation that could optimise sustainable place-making. Kraví Hora and De Site demonstrate different expectations from public (recreational) space, as described by Gibas (2011). The typical image of public greenery is an area which is 'offered' by the local authorities, who are responsible for managing it while at the same time setting rules which prescribe how spaces can be used. A public park offers limited opportunities for individuals to engage and interact with their surroundings and they may become passive 'consumers' of space.

At the Kraví hora allotments, internal rules allow and encourage personal agency. Gardeners are required to tend their plot and contribute to the maintenance of the common areas. Allotment functionaries point out that gardeners effectively take over the task of green space management, which would otherwise have to be funded from the city's budget. At the same time, the gardeners emphasise the importance of having an active way of spending their free time. Growing food is perceived as proper, meaningful work, a source of continuity, pride and self-fulfilment:

"I wouldn't go and sit in a park. I come here because here I get to do something, something is growing, and something remains after me."

Similar attitudes were observed in Ghent in discussions about the difference between De Site and alternative public spaces. The opportunities that De Site offers in terms of experimenting with a form of public participation, is currently not common in urban planning:

"Now people see a park as property of the city council that they are allowed to use. But that 'use' is pre-defined by the landscape architect that places two benches, or a play area for children, or a fountain. The landscape architect decides how the users can experience the park. We think now that it is time to turn this around. The city council is the owner. And that is it. The common, that is people living close to the park, should be able to use the park in the way they would like to use it."

The fact that such places can develop within temporal contexts which include short tenure agreements and uncertain futures, demonstrates the risks people can take when investing in places without having the security of continuation. It can be argued that a universal tradition of both household self-provision and municipal cultivation represents an asset that facilitates place-making through UA. Temporal spaces offer opportunities to experiment, as demonstrated in Ghent: 
"I think that the temporality has been of great value for De Site. It has created space to experiment. This will be more difficult in the park [being made permanently available]. In the park things have to look beautiful immediately. There will be much less room to experiment.

The lack of permanence, however, weakens the placemaking function of UA. This becomes very evident at De Site, where an 80-year old gardener responded to the proposed move with regret:

"We feel that there is no more place for us. Money matters more than we do."

Thus, on the one hand, the temporal character of land access at De Site opened up room to experiment but, on the other hand, it is not a solution to the need to overcome a sense of 'placelessness' and the demand for concrete places on the long term.

The facilitation of the place-making functions of UA requires a shift in roles and responsibilities in the governance of urban spaces. Different responses to this challenge are evident from the case studies. In Ghent, the city council has made new permanent space available in a park in the same neighbourhood. Here, the functional attributes of De Site are associated with a spatial designation of UA on the basis of UA's potential to create place. This contrasts with the situation in Brno, where, in one proposed scenario, the allotment garden is to be transformed into a park (without food production).

In Bristol, the place-making potential of UA is acknowledged via the Food Policy Council (FPC) - and EGCfunded projects but, in practice, this potential is difficult to integrate into urban planning in a fast-developing city faced with traditional spatial development needs and across local authority boundaries:

"Inertia in the political process is another challenge. How can politicians and planners be persuaded to consider cross-authority peri-urban issues when other agendas infrastructure and economic development - are perceived as more important?"

In particular, the special spatial value invested in the Blue Finger as a result of its fertility, seems very hard to accommodate strategically given the distribution of land ownership and the different functional attributes envisaged by Bristol City vs. South Gloucestershire Councils:

"The scale of the challenge is big - $90 \%$ of the land is owned privately and is not easily accessible by foot or bike. In addition, the price of land is very high, usually around € 7,000 an acre' [or € 14,875/ ha at the time of writing].”

Finally, it is unclear what will happen with the FPC's food plan under Bristol's new mayor, elected in 2016. While it has been argued that UA spaces can contribute to place-making, the way space is managed by the planning processes in many cities can be uniform, linear, and unable to accommodate easily the socio-cultural aspects of locality. As demonstrated here, a shift towards stronger place-making through multistakeholder realisation of UA can sit uneasily within traditional conceptions of urban planning and governance in two major ways.

First, our cases are examples of spaces which serve a collective interest and they are also governed by a group of users (not owners). Through their active participation, allotment members shape the place, which simultaneously enhances their attachment to it. While some people expect public green space to be accessible and undemanding, others are willing to invest more effort in co-producing these places, and require more secure conditions for their commitment. Such personal/collective involvement on what is technically public land, however, is hard to accommodate within the current functional categories of spatial planning.

Second, this has implications for the replicability of UA functions. The cases suggest that in order for UA to contribute to place-making, a certain degree of user autonomy, security and permanence is needed. This reflects the not-public, not-private nature of UA: while the risk of exclusivity ought to be considered, having the power to negotiate who is, or is not, a member of the group is instrumental for developing collective identity and focus on common goals. These are the starting points of collective place-making.

To summarise, we argue that to develop the full potential of UA as a contribution to creating meaningful places, issues of autonomy, collective governance and permanence should be considered in urban planning processes, especially as interest in UA grows. In this respect, insights from the literature on the commons might be useful. Many authors (e.g. Barron, 2017; Bennholdt-Thomsen, 2012; Eizenberg, 2012; Müller, 2012) have already traced similarities between governance in UA and of the 'traditional' commons (Ostrom, 1990). Contrary to the abstract space narrative, the commons are not diminished to an economic resource but they are socially mediated and created (Illich, 1992: 49). Apart from institutionalising autonomous collective governance, the commons thinking thus might be a way of giving more weight to lived experience as a spatial force. Finally, in their traditional form, the commons also have a strong sustainability dimension based on collective interest, self-control and the sense of responsibility towards future generations (Bailey et al., 2013).

\section{Conclusions}

This paper has sought to illuminate the spatial contexts surrounding urban agriculture in response to increasing scholarly interest and practical innovations in this arena. The cases explored here add to knowledge of UA in European 'second' cities, a departure from earlier UA scholarship which typically deals with larger metropolitan scales, or frames UA as an economic development opportunity in the Global South. The food initiatives explored in this article reveal what the authors see as a characteristic feature of $\mathrm{UA}$, namely the existence of intrinsic tensions associated with land use for food production. Such tensions are linked to urban land in different ways than to rural land, firstly because agricultural policy has harnessed the rural realm to economic productivity since the 1950 s while, conversely, modern economic development has largely divorced the city from the production of food.

One consequence of this binary is a growing interest among city dwellers in exploring the social, environmental and political possibilities of urban food production. These multiple functions of UA create multiple demands on land, which may compete with land use designations outlined within strategic development plans that contain land use categorisations assigned for non-agricultural economic functions. Our argument in this paper has been that the nature of the tension rests on diverging space narratives. While scholarship on urban agriculture is following advances and innovations in practice very closely, this spatial focus has created new insights into the governance of urban land. 
There are three main conclusions to draw from this investigation. First, through active and collective processes that arrange spaces with food as personal and culturally embedded practice, UA can transform spaces into distinctive places. This means that UA can have an important placemaking function.

Second, the case studies clearly show that the existing governance structures tied to planning policies offer limited scope for negotiating land use tensions and, in fact, add to them. Reasons for this include competition in demands for land (Brno and Bristol), and functionalist categorisations of city space (Bristol and Ghent). It is notable that in Bristol and Ghent there is significant municipal support for the strategic development of a sustainable food system through the localisation of food production. But the Bristol example reveals challenges in how competing sustainability issues are subordinated, and the Ghent case has been highly successful in creating a place of great value to its users within a fixed time-frame. Such creative solutions to the dynamic needs of the city are exciting, but money and energy is wasted if such experiences and practices are not considered in future developments of the place.

Third, our research has revealed that UA is positioned on the boundary between public and private space: public, in terms of being shared and owned by the municipality; private, in terms of protecting certain interests over others (as in the case of the Brno gardeners). To bolster efforts to find a consensual solution to the tensions linked to UA, we add our voices to others (Clifford and King, 1996; Sonnino, 2014; Tornaghi, 2016) in calling for a more equitable, temporal and iterative approach to urban development and place-making which is less (mono-)functionalist. Apart from creating physical spaces to develop urban agriculture through zoning (see Huang and Drescher, 2015; Maloney, 2013; McClintock et al., 2012), the institutionalisation of UA in urban planning strategies should also give thought to the delegation of autonomous governance over spaces suitable for UA. Such a call to institutionalise processes of place-making, however, is not new but yet another example of how collaborative placemaking could happen. In order to move forward, insights from the governance of the commons could possibly offer valuable lessons for urban planners and further research in this area is called for.

\section{Acknowledgment}

The authors wish to thank Robert Berry and Pieter Foré for their contributions in drawing the maps. We thank Richard Spalding for his help in relation to the Blue Finger case, and Wannes Degelin for his help in relation to De Site. We thank Elke Rogge and anonymous reviewers for feedback on earlier versions of the paper. Work on the Brno case was supported by the Czech Science Foundation, Grant No. GA14-33094S: 'Forms and norms of alternative economic practices in the Czech Republic'.

\section{References}

AGNEW, J. (2011): Space and place. In: Agnew, J., Livingstone, D. [eds.]: Handbook of geographical knowledge. London, Sage.

BAILEY, S., FARRELL, G., MATTEI, U. (2013): Protecting future generations through commons. Trends in Social Cohesion 26. Strasbourg Cedex, Council of Europe Publishing.
BARRON, J. (2016): Community gardening: cultivating subjectivities, space, and justice. Local Environment, 22(9): 1142-1158.

BARTHEL, S., FOLKE, C., COLDING, J. (2010): Socialecological memory in urban gardens - Retaining the capacity for management of ecosystem services. Global Environmental Change - Human and Policy Dimensions, 20(2): 255-265.

BENNHOLDT-THOMSON, V. (2012): Subsistence: Perspective for a Society Based on Commons. In: Bollier, D., Helfrich, S. [eds.]: The Wealth of the Commons: a world beyond market and state. (pp. 219224). Amherst: Levellers Press.

BHATTI, M. (2006): "When I'm in the garden I can create my own paradise": Homes and gardens in later life. Sociological Review, 54(2): 318-341.

BHATTI, M., CHURCH, A. (2001): Cultivating Natures: Homes and Gardens in Late Modernity. Sociology, 35(2): 365-383.

BLOMLEY, N. (2008): Making Private Property: Enclosure, Common Right and the Work of Hedges. Social \& Legal Studies, 17(3): 311-331.

BRISTOL FOOD POLICY COUNCIL (2013): A Good Food Plan for Bristol. Bristol, BFPC.

BROWN, K., CARTER, A. (2003): Urban Agriculture and Community Food Security in the United States : Farming from the City Center to the Urban Fringe. Venice, California. Available at: http://community-wealth.org/ sites/clone.community-wealth.org/files/downloads/ report-brown-carter.pdf

CAREY, J. (2011): Who feeds Bristol? Towards a resilient food plan. Bristol, Bristol City Council/Bristol NHS.

CAREY, J. (2013): Urban and Community Food Strategies. The Case of Bristol. International Planning Studies, 8(1): 111-128.

CLIFFORD, S., KING, A. (1996): From place to place: Maps and Parish Maps. London, Common Ground.

CLIFFORD, S., KING, A. (2006): England in Particular. London, Hodder \& Stoughton.

COHEN, N., REYNOLDS, K. (2014): Urban Agriculture Policy Making in New York's "New Political Spaces": Strategizing for a Participatory and Representative System. Journal of Planning Education and Research, 34(2): 221-234.

DAVENPORT, M. A., ANDERSON, D. H. (2005): Getting From Sense of Place to Place-Based Management: An Interpretive Investigation of Place Meanings and Perceptions of Landscape Change. Society \& Natural Resources, 18: 625-641.

DE HOOP, E., JEHLIČKA, P. (2017): Reluctant pioneers in the European periphery? Environmental activism, food consumption and "growing your own". Local Environment,1-16.Doi: 10.1080/13549839.2017.1289160

DE MAGALHAES, C. P. H., MADANIPOUR, A. (2002): Assessing Institutional Capacity for City Centre Regeneration: Newcastle's Grainger Town. In: Cars, P. H. et al., [eds]: Urban Governance, Institutional Capacity and Social Milieux (pp. 45-62). Aldershot, Ashgate. 
DE ZEEUW, H., DUBBELING, M. (2009): Cities, Food and Agriculture: Challenges and the Way Forward. Working paper No. 3. Leusden, RUAF Foundation.

DUFFKOVÁ, J. (2002): První a druhý domov. Vývoj české záliby $\mathrm{v}$ chataření a chalupaření z pohledu sociologie. Př́tomnost, 2: 29-31.

EIZENBERG, E. (2012): Actually Existing Commons: Three Moments of Space of Community Gardens in New York City. Antipode, 44(3): 764-782.

FARINELLI, F. (2003): Geografia. Un'introduzione ai modelli del mondo. Turin, Einaudi.

FRANZ, M., GULES, O., PREY, G. (2008): Place-Making and 'Green' Reuses of Brownfields in the Ruhr. Tijdschrift voor economische en sociale geografie, 99(3): 316-328.

FRIEDMANN, J. (2010): Place and Place-Making in Cities: A Global Perspective. Planning Theory and Practice, 11(2): 149-165.

FÜRST, D., LAHNER, M., ZIMMERMAMM, K. (2004), Neue Ansätze Integrierter Stadtteilentwicklung: Placemaking und Local Governance. Erkner, IRS.

GIBAS, P. (2011): Falešná zeleň a rajské zahrady. A2, 19: 2-13 [online]. [cit. 01. 09. 2016]. Available at: http:// www.advojka.cz/archiv/2011/19/falesna-zelen-a-rajskezahrady.

GIBSON-GRAHAM, J. K. (2014): Rethinking the Economy with Thick Description and Weak Theory. Current Anthropology, 55(9): 147-153.

GRAY, D. (2004): Doing research in the real world. London, SAGE Publications.

HUANG, D., DRESCHER, M. (2015): Urban crops and livestock: The experiences, challenges, and opportunities of planning for urban agriculture in two Canadian provinces. Land Use Policy, 43: 1-14.

ILLICH, I. (1992): In the Mirror of the Past: Lectures and Addresses, 1978-1990. Marian Boyars.

KOOPMANS, M. E., METTEPENNINGEN, E., KUNDA, I., KEECHE， D., TISENKOPFS, T. (2017): Creating synergies around food in cities. Urban Agriculture \& Regional Food Systems, 2(1): 1-9.

LEFEBVRE, H. (1991): The Production of Space (translated by Donald Nicholson). Oxford, Blackwell.

LA ROSA, D., BARBAROSSA, L., PRIVITERA, R., MARTINICO, F. (2014): Agriculture and the city: A method for sustainable planning of new forms of agriculture in urban contexts. Land Use Policy, 41: 290-303.

LOVELL, S. T. (2010): Multifunctional Urban Agriculture for Sustainable Land Use Planning in the United States. Sustainability, 2(8): 2499-2522.

MALONEY, S. A. (2013): Putting Paradise in the Parking Lot: Using Zoning to Promote Urban Agriculture. Notre Dame Law Review, 88(5): 2551.

MCCLINTOCK, N. (2014): Radical, reformist, and gardenvariety neoliberal: coming to terms with urban agriculture's contradictions. Local Environment, 19(2): 147-171.

MCCLINTOCK, N., WOOTEN, H., BROWN, A. (2012): Toward a food policy 'first step' in Oakland, California:
A food policy council 's efforts to promote urban agriculture zoning. Journal of Agriculture, Food Systems and Community Development, 2(4): 15-42.

MCCLINTOCK, N., MAHMOUDI, D., SIMPSON, M., PEREIRA SANTOS, J. (2016): Socio-spatial differentiation in the Sustainable City: A mixed-methods assessment of residential gardens in metropolitan Portland, Oregon, USA. Landscape and Urban Planning, 148: $1-16$

MERRIFIELD, A. (1993): Place and Space: A Lefebvrian Reconciliation. Transactions of the Institute of British Geographers, 18(4): 16-18.

MÜLLER, C. (2012): Practicing Commons in Community Gardens: Urban Gardening as a Corrective for Homo Economicus. In: Bollier, D., Helfrich, S. [eds.]: The Wealth of the Commons: A World beyond market and state. (pp. 219-224). Amherst, Levellers Press.

OPITZ, I., BERGES, R., PIORR, A., KRIKSER, T. (2016): Contributing to food security in urban areas: differences between urban agriculture and peri-urban agriculture in the Global North. Agriculture and Human Values, 33(2): 341-358.

OSTROM, E. (1990): Governing the commons: The evolution of institutions for collective action. Cambridge, Cambridge University Press.

PARHAM, S. (2015): Food and Urbanism: The Convivial City and a Sustainable Future. London, Bloomsbury.

PAUKNEROVÁ, K., GIBAS, P. (2011): The struggle over nature and relaxation in (sub)urban space: The case of garden colonies in Kbely, Prague 19. Lidé města, 15(2): 221-233.

PERDIKOGIANNI, I. (2007): From space to 'Place': the role of space and experience in the construction of 'place'. In: $6^{\text {th }}$ International Space Syntax Symposium. pp. 52-1-52-12.

PROSHANSKY, H. M. et al. (1983): Place-identity: Physical world socialization of the self. Journal of Environmental Psychology, 3(1): 57-83.

PURCELL, M. (2001): Neighborhood Activism among Homeowners as a Politics of Space. The Professional Geographer, 53(2): 178-194.

RELPH, E. (1976): Place and placelessness. London, Pion

SMITH, V. M., GREEN, R. B., SILBERNAGEL, J. (2013): The social and spatial dynamics of community food production: A landscape approach to policy and program development. Landscape Ecology, 28(7): 1415-1426.

ROGGE, E., KERSELAERS, E., PROVE, C. (2016): Envisioning opportunities for agriculture in peri-urban areas. In: Andersson, K. et al. [eds.]: Metropolitan Ruralities: Research in Rural Sociology and Development, 23: 161-189. Emerald Group Publishing Limited.

SCHEROMM, P. (2015): Motivations and practices of gardeners in urban collective gardens: The case of Montpellier. Urban Forestry and Urban Greening, 14(3): 735-742.

SCHMELZKOPF, K. (2002): Incommensurability, Land Use, and the Right to Space: Community Gardens in New York City 1. Urban Geography, 23(4): 323-343. 
SONNINO, R. (2014): The new geography of food security: exploring the potential of urban food strategies. The Geographical Journal, 182(2): 190-200.

SOVOVÁ, L. (2015): Self-provisioning, Sustainability and Environmental Consciousness in Brno Allotment Gardens. Sociální Studia/Social Studies, 3: 11-26.

SPILKOVA, J., VAGNER, J. (2016): The loss of land devoted to allotment gardening: The context of the contrasting pressures of urban planning, public and private interests in Prague, Czechia. Land Use Policy, 52: 232-239.

THE BRISTOL POST LIVE UPDATES (2015): Bailiffs move in to evict Stapleton Allotment tree-top protesters. Bristol Post, 12.03.2015.
TORNAGHI, C. (2014): Critical Geography of Urban Agriculture. Progress in Human Geography, 38(4): 551-567.

TORNAGHI, C. (2016): Urban Agriculture in the Food-Disabling City: (Re)defining Urban Food Justice, Reimagining a Politics of Empowerment. Antipode, 49(3): 781-801.

VAN VEENHUIZEN, R. [ed.] (2006): Cities Farming for the Future - Urban Agriculture for Green and Pro ductive Cities. RUAF Foundation, IDRC and IIRR Publishing.

ZHU, J. (2012): Development of sustainable urban forms for high-density low-income Asian countries: The case of Vietnam. The institutional hindrance of the commons and anticommons. Cities, 29(2): 77-87.

Please cite this article as:

KOOPMANS, M. E., KEECH, D., SOVOVÁ, L., REED, M. (2017): Urban agriculture and place-making: Narratives about place and space in Ghent, Brno and Bristol. Moravian Geographical Reports, 25(2): 154-165. Doi: 10.1515/mgr-2017-0014. 